\title{
CONTABILIDADE DE CUSTOS PARA GESTÃO DO MEIO AMBIENTE
}

\author{
Autor: Aracéli Cristina de Souza Ferreira \\ Doutoranda em Controladoria e Contabilidade pela FEA/USP
}

\section{Introdução}

As preocupações relativas ao meio ambiente, que tem assolado a humanidade nestes últimos tempos, decorrem da evidência que atividades humanas de modo geral, empresas, governo e indivíduos, não se preocupam com a preservação, com o manter a terra limpa, em condições de dar continuidade à vida.

Assim, as empresas, cujas atividades tem sido potencialmente uma das maiores causadoras da poluição que assola o planeta, quer seja por pressões políticas e sociais, quer seja por sua própria conscientização têm procurado colocar a questão ambiental como um importante tópico a ser considerado em suas decisões, sejam elas de investimentos futuros, de lançamentos de novos produtos ou até mesmo na reformulação de produtos existentes.

Além das empresas, os governos dos países estão atentos a esses mesmos problemas, pois além de terem também atividades poluidoras, são os que têm os maiores encargos delas decorrentes, seja na área de saúde e previdência causadas por doenças provocadas pela poluição ou agindo diretamente na despoluição e na regulamentação das atividades.

Normalmente, em assuntos onde estão empresas e governo e que envolvem recursos econômicos, são necessárias informações que possam representar os resultados obtidos pelas diversas entidades no desempenho de suas atividades econômicas. Assim, faz-se mister que a Contabilidade, como instrumento de informações para a tomada de decisões, possa desenvolver e incorporar em seus conceitos e métodos formas de registrar e mensurar os eventos econômicos relativos ao meio ambiente.

Considerando a importância do tema e a imprescindível participação da Contabilidade em suas discussões é que se está desenvolvendo uma pesquisa, como parte de um projeto de doutoramento na FEA/USP, de como a Contabilidade, principalmente relativa aos custos de produção, pode gerar informações que sejam úteis aos gestores das empresas e ao governo para a gestão ambiental.

As idéias que a seguir se desenvolvem devem ser consideradas dentro de seus limites, ou seja, de um trabalho de pesquisa ainda não concluído e cujo objetivo é propor a discussão do tema sob uma determinada ótica.

\section{Gestão Ambiental}

O meio ambiente hoje, para ser gerido, tem em suas variáveis não só o aspecto poluição/despoluição, mas também quanto custa isso, tanto em termos econômicos como em termos sociais. É preciso dar melhores condições de vida ao homem, com a geração de riqueza mas também preservando o acesso de futuras gerações aos recursos naturais para que, em nenhum momento no futuro, a cadeia do desenvolvimento seja quebrada, a isso chama-se desenvolvimento sustentável.

O grande desafio do desenvolvimento sustentável envolve diversos obstáculos a serem superados. As questões se desdobram, por exemplo, preservar o ambiente muitas vezes significa não produzir determinados produtos, ou então, incorrer em custos extremamente altos para produzi-los sem afetar o ambiente, tornando-os com isso caros, sem condições de serem adquiridos pelo consumidor final. Um produto cujo preço não seja competitivo corre o risco de levar uma empresa à falência e isso geraria desemprego, e todas as conseqüências

Caderno de Estudos nº12, São Paulo, FIPECAFI, Setembro/1995 
sociais inerentes a essa situação.

Seria inocente dizer que a empresa não está preocupada com o mercado. Em última análise, ele é o grande balizador dos rumos que ela poderá seguir. E, mesmo que a sociedade pressione para que não se polua, as empresas terão como um dos fatores limitativos na sua intenção de não poluir, o impacto dos custos que um programa antipoluição terá sobre o custo final de seu produto. Um outro fator a ser considerado são as exigências legais, que impõem um controle cada vez mais rígido sobre os níveis de poluição.

Além disso, há de se convir, principalmente no Brasil, cujo povo é em sua maioria semi-analfabeto, onde uma recessão persiste há anos e cuja perspectiva de voltar a crescer e sair da condição de subdesenvolvimento é de, no mínimo médio prazo, por exemplo, o consumidor brasileiro na eventualidade de escolher entre um produto que não polui e é mais caro e um que polui, porém é mais barato, a probabilidade de que sua escolha recaia sobre o segundo é bem maior.

E é sob essa perspectiva que a empresa vai decidir sobre o processo produtivo a ser adotado. A sobrevivência do meio-ambiente pode ser vista como uma questão de médio e longo prazo, já a questão da sobrevivência do negócio é um tópico que, do ponto de vista do empresário, é de curto prazo e lhe é mais sensível. Assim, aspectos econômicos e sociais estarão sempre permeando essas questões.

Há de se convir que o empresariado pode ser levado a adotar programas antipoluição através de medidas compulsórias, elaboradas pelo governo. Entretanto, além disso, existem questões mercadológicas como para aqueles que negociam ou pretendem negociar com o mercado externo. Alguns países podem adotar medidas restritivas a produtos cujo processo de elaboração gere poluição e outros não.

Existem vários exemplos de como a questão do meio ambiente pode impactar o resultado das empresas, o que não se sabe exatamente é como mensurar esses efeitos, pois os instrumentos de informações disponíveis hoje são considerados insuficientes para evidenciar essas questões e permitir uma adequada decisão.

A relevância do problema relativo à falta de informações sobre o problema ambiental nas empresas, discutida na RIQ/92 e, segundo um documento divulgado pelo Institute of Tropical Ecology Ecotropic , "é muito difícil converter certos custos em dinheiro" e deveriam ser realizadas.

"Análises em favor da necessidade de se aplicar valor monetário para os custos do meio ambiente e aqueles que se considere indicadores físicos como o meio mais neutro de mensuração desses custos". 1

Não existe, ainda, um sistema de informações estruturado, consistente e que mostre claramente como esses processos de proteção ambiental impactam o resultado da empresa e ainda, que possam servir de instrumento para uma política econômica de governo de subsídio ou restrições a determinado produto ou região.

\section{Auditoria Ambiental}

A Contabilidade, mais precisamente a auditoria, para atender a mais essa necessidade de informação sobre as empresas, começou a desenvolver estudos, principalmente a partir do fato ocorrido na Índia com a empresa "Union Carbide", cuja tragédia resultou em centenas de mortes com o vazamento de gases, as ações da empresa despencaram nas Bolsas de Valores, inclusive porque as famílias afetadas pela desgraça deveriam ser indenizadas. Mais recentemente, tragédia parecida aconteceu no Alaska/USA, com o vazamento de óleo no mar provocado pela empresa "Exxon", também neste caso o impacto foi sentido no preço das ações. Nos dois

${ }^{1}$ Report on international Multidisciplinary Workshop on Environmental Accounting. Institute of Tropical ecology Ecotropic Rio de janeiro. junho/92. Págs. 1 e 2.

Caderno de Estudos nº12, São Paulo, FIPECAFI, Setembro/1995 
Contabilidade de Custos para Gestão do Meio Ambiente 3

casos, percebeu-se que ambas as empresas não tinham em suas demonstrações contábeis, tanto no Balanço Patrimonial e nem sequer em notas explicativas, nenhuma menção aos prováveis riscos que elas estavam incorrendo com a poluição do meio ambiente e a conseqüente necessidade de indenizar pessoas ou governos, ou ainda, com gastos de recuperação ambiental pelos danos causados por atividades de sua responsabilidade.

Desses fatos, resultaram preocupações principalmente nas empresas de auditoria, que deveriam atestar se as demonstrações contábeis estavam de acordo com os princípios de Contabilidade e com a legislação legal mas que, até aquele momento, não focavam em suas análises as contingências relativas ao meio ambiente. A auditoria, entretanto, é uma análise a "posteriori" e, inclusive, passiva. O fato ocorre, polui-se e depois atesta-se que o passivo ambiental foi considerado nas demonstrações contábeis através de provisões ou reservas para contingências, conforme o caso.

Essas informações, entretanto, são muito pobres em se tratando de uma gestão ambiental voltada para o desenvolvimento sustentável. Além disso, a Contabilidade não pode se esquecer de seus dois postulados o da Entidade e o da Continuidade, que justificam uma outra abordagem contábil para o problema do meio ambiente.

\section{Contabilidade Ambiental}

Embora a Contabilidade seja conhecidamente um sistema de informações formal e estruturado, que tem entre seus objetivos principais informar para o controle do patrimônio, para a avaliação de desempenho e para a tomada de decisão, para atingir a esses fins ela necessita de um corpo de conceitos e de uma metodologia que possam representar de modo objetivo os eventos econômicos ocorridos nas empresas. Ocorre, porém, que o ambiente em que esses eventos estão acontecendo está recebendo interferências de variáveis que até há algum tempo atrás não eram consideradas significativas e, portanto, não eram objeto de classificação conceitual e metodológica pela Contabilidade, como é o caso da questão ambiental. Por isso, faz-se mister estudar até que ponto a metodologia contábil está preparada para atender aos reclamos deste problema atualmente imposto às empresas e à sociedade como um todo.

Assim, a Contabilidade, como meio de informação das transações e evento econômicos, passíveis de mensuração, realizados pelas empresas e entidades, não pode ficar à margem das discussões sobre os problemas ecológicos e a busca de meios para resolvê-los. A abordagem social da Contabilidade obriga-a a participar ativamente na pesquisa sobre como informar os eventos realizados pelas organizações que podem impactar o meio ambiente e, concomitantemente, cuidar da mensuração desses eventos.

As informações contábeis podem classificar-se em dois tipos sobre os Ativos e Passivos Ambientais, que deveriam ser apresentados num Balanço Social e sobre os custos da poluição de/ou processos de não poluição decorrente do processo produtivo.

À parte as considerações sobre se a Contabilidade é uma ciência ou um método, ambas as correntes concordam que seus objetivos são, de modo abrangente, informar para

1)o controle do Patrimônio

2)a avaliação do desempenho;

3)a tomada de decisão.

Esses objetivos, para que possam ser alcançados, dependem, entre outras coisas, da capacidade que a Contabilidade tem em acumular informações referentes às transações econômicas realizadas pelas 
organizações e, ainda, em comunicar aos seus diversos usuários os resultados alcançados pela entidade, em função dessas transações.

Aqueles que se utilizam às informações contábeis são tradicionalmente classificados em:

- usuários internos;

- usuários externos

$\mathrm{Na}$ primeira categoria incluem-se os proprietários, administradores e gerentes de uma entidade empresarial e na segunda, o governo, bancos, fornecedores, clientes, investidores reais e potenciais, enfim, aqueles que direta ou indiretamente transacionam com esta entidade.

Tendo em vista os diversos tipos de transações a que se submetem as empresas e às variáveis envolvidas, a Contabilidade foi transformando-se ao longo do tempo, de modo a tentar responder com um razoável nível de satisfação, aos anseios de seus usuários Assim, dividiu-se em duas grandes vertentes, sob as quais criaram-se metodologias apropriadas e cujos objetivos tendem a atender situações específicas, são elas a Contabilidade financeira e a Contabilidade Gerencial.

Entretanto, qualquer uma delas está subordinada aos Postulados que regem a Contabilidade, quais sejam a Entidade e a Continuidade.

ludícibus, citando Moonitz, coloca que a entidade é:

"a unidade econômica que tem controle sobre recursos, aceita a responsabilidade por tarefas e conduz à atividade econômica....".

O mesmo autor define a Contabilidade como:

"empreendimentos em andamento (going concern), até circunstância esclarecedora em contrário, e, como tais, seus ativos devem ser avaliados de acordo com a potencialidade que tem de gerar benefícios futuros para a empresa,...."3

Os dois postulados estão interligados, deve- se entender que a Contabilidade atua em uma Entidade em Continuidade.

A Continuidade é o postulado que direciona a entidade para o futuro, para o desenvolvimento, para o crescimento. Para a Contabilidade realizar a mensuração dos fatos econômicos, é condição "sine qua non" que a entidade tenha intenção e possibilidade de continuar existindo, ou seja, sua existência está intrinsecamente ligada à sua capacidade de gerar benefícios futuros.

Analogamente,.esses postulados valem também para a humanidade, pois para a sua existência é fundamental. imprescindível que ela tenha possibilidade de continuar existindo, e intenção firme o suficiente para superar as dificuldades que venham nisso interferir.

\section{Quadro 1 - BALANÇO PATRIMONIAL AMBIENTAL}

\footnotetext{
${ }^{2}$ Iudícibus, Sérgio de - Teoria da Contabilidade. Editora Atlas, São Paulo, 1980, pág. 49.

${ }^{3}$ Idem, ibidem, pág. 50

Caderno de Estudos nº12, São Paulo, FIPECAFI, Setembro/1995
} 


\section{ATIVO CIRCULANTE}

Estoques

Custo de aquisição/produção

(-) Custos ambientais

\section{ATIVO PERMANENTE}

Equipamentos

Polui dores

Não poluidores

Anti-poluição

\section{PASSIVO CIRCULANTE}

Provisões $\mathrm{p} /$ passivos ambientais

\section{EXIGÍVEL A LONGO PRAZO}

Provisões $\mathrm{p} /$ passivos ambientais

\section{PATRIMÔNIO LÍQUIDO}

Reservas de contingências para

passivos ambientais

Já a demonstração de resultado do exercício, para evidenciar os custos de produção relativos ao meio ambiente dos produtos vendidos, deveria ter a seguinte formatação mínima:

\title{
Quadro II - DEMONSTRAÇÃO DO RESULTADO AMBIENTAL
}

\section{RECEITA DE VENDAS}

(-) CUSTO DOS PRODUTOS VENDIDOS

Custos de produção

Custos ambientais da produção

\section{LUCRO BRUTO}

\section{$(-)$ DESPESAS OPERACIONAIS}

\author{
Despesas de Vendas \\ Despesas Administrativas \\ Despesas Financeiras + Receitas Financeiras \\ Despesas Ambientais (inclusive provisões)
} LUCRO OPERACIONAL AMBIENTAL

As Demonstrações Contábeis Ambientais acima propostas podem ser um instrumento a mais na gestão ambiental, tanto por parte dos governos como das empresas e da própria sociedade. O governo teria condições de acompanhar se os gastos com o meio ambiente estão de acordo com as políticas ambientais determinadas, e também com a capacidade financeira de cada empresa em particular, como parte de uma política de desenvolvimento sustentável. A sociedade poderia acompanhar se aqueles produtos intitulados não poluidores, realmente o são, pois seria possível verificar efetivos gastos realizados para proteger o meio ambiente durante 0 processo produtivo e também na estocagem de materiais e produtos, quando for o caso. Isso pode ser feito, inclusive, individualizando os custos de proteção por produto, como a própria Contabilidade de Custos já o faz sem considerar o meio ambiente. 
É preciso lembrar, entretanto, que, ao aceitar como dedutíveis, para efeito do cálculo do imposto de renda a pagar, as despesas de provisões para passivos ambientais, o governo poderá incorrer num incentivo a que, empresas poluidoras continuem poluindo, porém, registrando em seus balanços futuros gastos com indenizações por danos relativos ao meio ambiente, sem se preocuparem com modificações em suas atividades que resultem em menos poluição. Com isso, os recursos do Estado seriam menores, pelo menor pagamento de imposto, mas seus gastos com saúde, aposentadorias, despoluição, entre outros, continuariam aumentando. Afinal, os custos de poluir é individualizado, a despoluição, entretanto, é socializada.

\section{Conclusão}

É indiscutível que a questão ambiental, ainda por muito tempo, será pauta de importantes decisões a serem tomadas tanto por governos como pela sociedade como um todo. Não se poderá gerir a sociedade e seu desenvolvimento sem gerir, ao mesmo tempo, o meio ambiente.

A Contabilidade, como um dos principais instrumentos de informação para a gestão de empresas e de governo, não pode deixar de desenvolver métodos capazes de incorporar às suas demonstrações informações específicas sobre o meio ambiente, relativo tanto à poluição quanto à despoluição. Principalmente devido ao postulado da Continuidade, que pressupõe a existência de uma entidade por prazo infinito, o que se adeqüa perfeitamente à entidade maior, o nosso planeta.

Além disso, é fundamental que os contadores assumam para si, o que eles perfeitamente conhecem ao analisarem o Balanço Patrimonial de uma empresa: Ativos maiores que Passivos indicam uma boa situação patrimonial. Assim, é de se supor que, também em sua atuação profissional, os contadores sejam mais Ativos que Passivos. O meio ambiente requer esse tipo de postura. É preciso identificar, registrar e mensurar os impactos ecológicos causados por processos produtivos no momento em que ocorrem. O registro, apenas, de contingências ambientais passivas demonstra o fato consumado, uma ação passiva diante da gravidade do problema.

Mais do que nunca, a Contabilidade deve produzir informações que permitam uma gestão ambiental voltada para o desenvolvimento sustentável, para a continuidade!

Caderno de Estudos nº12, São Paulo, FIPECAFI, Setembro/1995 